\title{
QUALIDADE FISIOLÓGICA DE SEMENTES DE FEIJÃO TRATADAS COM SORO DE LEITE BOVINO
}

\author{
Gabriela Berguenmaier de Olanda ${ }^{1}$ \\ Rosemeri Berguenmaier de Olanda ${ }^{2}$ \\ Ricardo Batista Job ${ }^{3}$ \\ Irajá Ferreira Antunes ${ }^{4}$ \\ Gilberto Antônio Peripolli Bevilaqua ${ }^{5}$
}

Resumo: Os resíduos gerados pela cadeia agroindustrial do leite têm se mostrado como uma problemática, principalmente pelo volume produzido. Dessa forma, o seu reuso evidencia-se como uma possibilidade na agricultura. O objetivo do trabalho foi avaliar o efeito de diferentes doses de soro de leite bovino sobre 2 cultivares de sementes de feijão. Para isso, sementes de feijão da cv. Carioca e Expedito foram embebidas por uma hora nas doses de 0\% (testemunha), 20\%, 40\%, 60\% e 80\%.de soro de leite bovino e em seguida semeadas em bandejas contendo substrato vermiculita. As variáveis analisadas foram primeira contagem (4 dias) e germinação final (9 dias). O delineamento experimental foi inteiramente casualidade, em esquema fatorial 2 × 5 e para a análise dos dados foi realizada a análise da variância ao nível de 5\% de probabilidade. Como resultado, o soro de leite bovino não afetou a qualidade fisiológica das sementes de feijão nas condições desse estudo.

Palavras-chave: Agricultura familiar; Phaseolus vulgaris L.; Produção orgânica; Resíduos agroindustriais.

\footnotetext{
${ }^{1}$ PPG em Sistemas de Produção Agrícola Familiar/UFPel, Brasil. E-mail: gabiolanda@hotmail.com.

2 EMATER-RS, Brasil. E-mail: rosemereolanda@yahoo.com.br.

3 PPG em Sistemas de Produção Agrícola Familiar/UFPel, Brasil. E-mail: ricardo_job@yahoo.com.br.

${ }^{4}$ EMBRAPA Clima Temperado, Brasil. E-mail: iraja.antunes@embrapa.br.

5 EMBRAPA Clima Temperado, Brasil. E-mail: gilberto.bevilaqua@embrapa.br.
} 